\title{
First description of cardiomyopathy syndrome (CMS)-related lesions in wild Atlantic salmon Salmo salar in Norway
}

\author{
Trygve T. Poppe ${ }^{1, *}$, Sverre L. Seierstad ${ }^{2}$ \\ ${ }^{1}$ Norwegian School of Veterinary Science, Department of Morphology, Genetics and Aquatic Biology, PO Box 8146 Dep., \\ 0033 Oslo, Norway \\ ${ }^{2}$ District Veterinary Officer, Norwegian Animal Health Authority, 8820 Dønna, Norway
}

\begin{abstract}
This report represents the first diagnosis of cardiomyopathy syndrome (CMS) in migrating, wild Atlantic salmon Salmo salar from 1 major river and off the coast of Norway. Previously, this disease has been diagnosed only in farmed Atlantic salmon. The possible significance of the disease in wild stocks of salmon is discussed.
\end{abstract}

KEY WORDS: Cardiomyopathy syndrome $\cdot$ CMS $\cdot$ Salmo salar $\cdot$ Wild salmon

Resale or republication not permitted without written consent of the publisher

Cardiomyopathy syndrome (CMS) was originally identified as a disease in sea-farmed Atlantic salmon Salmo salar in Norway in 1985 (Amin \& Trasti 1988, Ferguson et al. 1990). The disease has subsequently been diagnosed in the Faeroe Islands (Poppe \& Sande 1994) and Scotland (Rodger \& Turnbull 2000) Although its aetiology remains unknown, a nodavirus-like agent has been proposed by Grotmol et al. (1997). While the disease typically causes only a low-grade acute mortality in large fish prior to slaughter, morbidity may be high and accumulated mortality considerable, lasting for several months.

Gross disease signs in terminal stages include lethargy, swollen abdomen, ventral petecchiation and exopthalmia. Necropsy typically reveals haemopericardium, ascites, visceral petecchiae, and general congestion. Histologically, the disease is characterized by degeneration and necrosis of the inner, spongious myocardium of the ventricle and the atrium, infiltration with lymphocytes and macrophages, and proliferation of the endocardium (endo- and myocarditis) (Ferguson 1989, p. 116-117, Bruno \& Poppe 1996, p. 140-141). Lesions in affected populations may vary from minute, scattered foci to entire involvement of the ventricular spongious myocardium and atrium. Typically, only fish with fully developed terminal lesions including thrombosis in the atrium and haemopericardium succumb to the disease. So far, CMS has only been described from farmed Atlantic salmon.

Materials and methods. During a routine histological survey of the hearts of wild Atlantic salmon (50 broodfish caught in September 2001 in the River Namsen $\left[64^{\circ} 30^{\prime} \mathrm{N}, 12^{\circ} 10^{\prime} \mathrm{E}\right]$, and 9 fish caught in a sea trap off the coast of Nordland county $\left[66^{\circ} 06^{\prime} \mathrm{N}\right.$, $12^{\circ} 29^{\prime} \mathrm{E}$ ] in July 2002), characteristic hypercellular foci were identified in the spongious myocardium in 2 fish from the River Namsen and in 2 fish $(5$ and $10 \mathrm{~kg}$ ) caught in a trap off the coast. The fish were judged as normal, healthy individuals when they were caught.

Results and discussion. Closer examination of haematoxylin and eosin (H\&E)-stained ventricles revealed multifocal areas with loss of striation, myodegeneration and vacuolation of the subendocardial space. There was extensive macrophage and lymphocyte infiltration and scattered hypertrophied myocyte nuclei in the affected areas (Fig. 1). Similar lesions were found in a small piece of atrium attached to one of the ventricles. No further lesions were identified in the hearts and no other organs were available for examination. The lesions were judged to be identical to those described for early stages of CMS in farmed Atlantic salmon (Amin \& Trasti 1988, Ferguson 1989, Ferguson et al. 1990).

The origin of the sampled fish could be questioned. Salmon escaping from fish farms is considered a big problem in Norway and escapees are common in many rivers. The people responsible for sampling the fish are experienced fishermen or fish biologists well aware of the problem with escapees, and they claim that these fish 


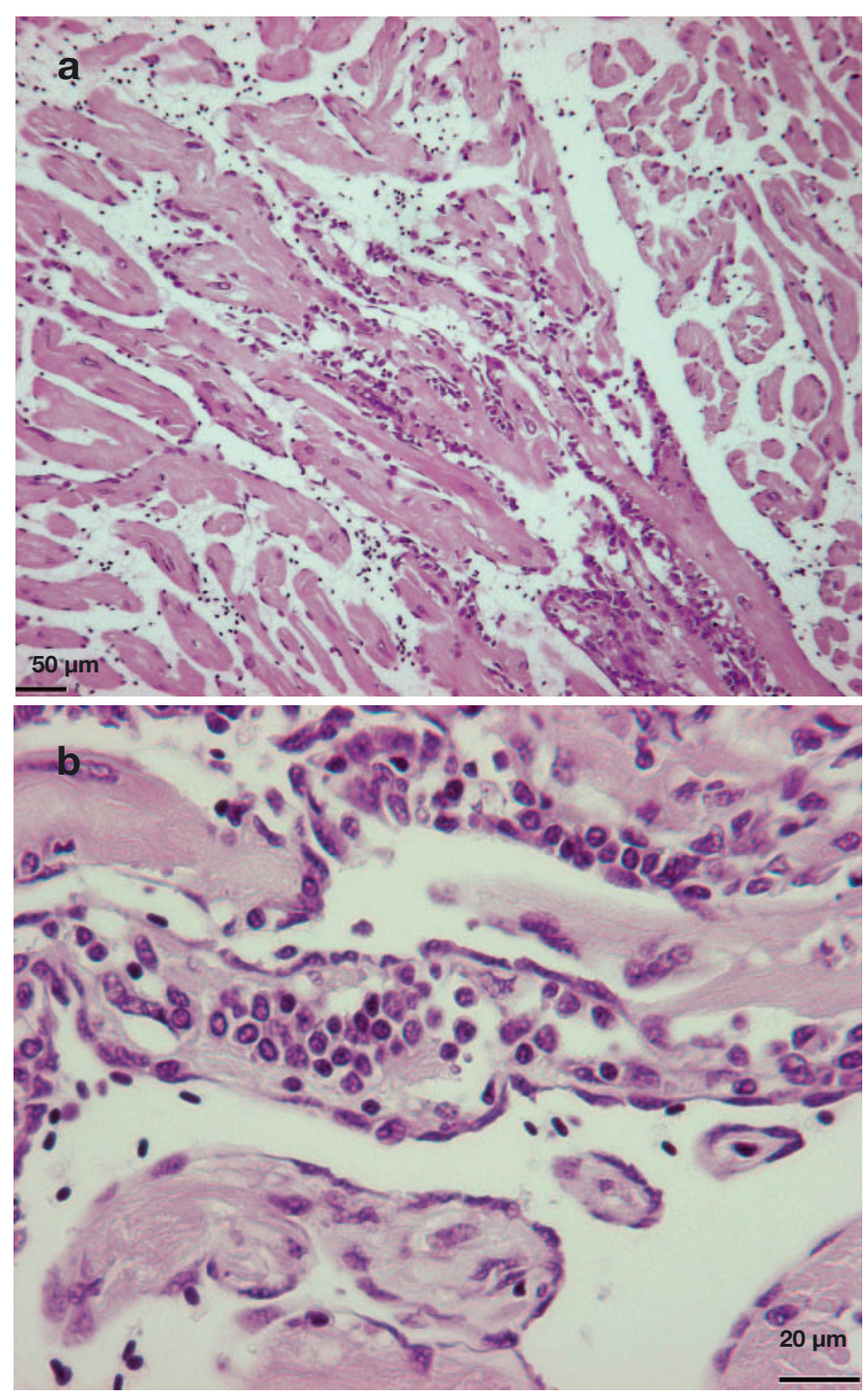

Fig. 1. Salmo salar with CMS. (a) Ventricular spongious myocardium of wild salmon showing foci with myodegeneration and infiltration of macrophages and lymphocytes (H\&E); (b) higher magnification of area in (a)

were phenotypically beyond doubt wild fish. All fish classified as 'wild' (based on external appearance) were also examined for post-immunization peritonitis and organ adhesions characteristic for farmed fish as described by Lund et al. (1995), with negative results. Furthermore, scale readings for the 50 fish from the River Namsen confirmed that these were indeed wild fish, with the growth pattern characteristic for wild specimens. We therefore consider it highly probable that these individuals were indeed wild fish, and not escapees.

CMS is a chronic, slowly progressing disease, whereby affected foci gradually extend and fuse to involve the entire spongious myocardium and atrium in the terminal stages of the disease. In farmed fish with terminal lesions, rupture of the atrium or sinus venosus typically occurs after moderate stress such as feeding, grading, transportation, or under suboptimal rearing conditions, e.g. algal blooms, etc. The significance for migrating wild fish can only be surmised, but it is considered likely that cardiac function will be severely compromised during long and strenuous upstream migration in fast rivers. It is therefore likely that migratory fish with pronounced lesions will not be able to handle energetically demanding situations.

Hearts of wild fish have been scanned on a regular basis by the present authors, and no sign of CMS has hitherto been found in them since the disease was first diagnosed in farmed salmon in 1985 (T. Poppe unpubl.). The fact that CMS lesions now have been diagnosed in wild fish supports a viral aetiology. The reservoir of a possible virus is unknown, but is likely to be found in the marine environment. From the present findings, CMS can be considered a potential threat to the wild Atlantic salmon populations.

These findings clearly reveal the need for further surveys in order to identify the prevalence of this important disease in wild salmon in different regions. Challenge experiments should also be undertaken to investigate the risk of transmission.

Acknowledgements. The authors would like to thank Anton Rikstad, Svein Romunstad and Ove Atle Hov for assistance during sampling of wild fish, Ms. May-Britt Johansen for excellent technical assistance in the preparation of slides, and Dr. Erik Sterud for valuable assistance with figures.

\section{LITERATURE CITED}

Amin AB, Trasti J (1988) Endomyocarditis in Atlantic salmon in Norwegian seafarms. Bull Eur Assoc Fish Pathol 8:70-71

Bruno DW, Poppe TT (1996) A colour atlas of salmonid diseases. Academic Press, London

Ferguson HW (1989) Systemic pathology of fish. Iowa State University Press, Ames

Ferguson HW, Poppe T, Speare DJ (1990) Cardiomyopathy in farmed Norwegian salmon. Dis Aquat Org 8:225-231

Grotmol S, Totland GK, Kryvi H (1997) Detection of a nodavirus-like agent in heart tissue from reared Atlantic salmon Salmo salar suffering from cardiac myopathy syndrome (CMS). Dis Aquat Org 29:79-84

Lund RA, Midtlyng PJ, Hansen LP (1995) Identification of Atlantic salmon escaped from fish farms by effects of disease prevention vaccination. NINA Fagrapp 12:1-14

Poppe TT, Sande RD (1994) Cardiomyopathy in farmed Atlantic salmon: a review, introducing an ultrasound technique for clinical examination. Norwegian School of Veterinary Science, Oslo

Rodger H, Turnbull T (2000) Cardiomyopathy syndrome in farmed Scottish salmon. Vet Rec 146:500-501

Submitted: January 6, 2003; Accepted: April 15, 2003

Proofs received from author(s): August 12, 2003 